\title{
HUBUNGAN PENGETAHUAN DENGAN KEJADIAN FLOUR ALBUS PADA WANITA USIA SUBUR DI WILAYAH PUSKESMAS LABUHAN RASOKI PADANGSIDIMPUAN TENGGARA
}

\author{
Juliana Lubis ${ }^{1}$, Nurhanifah Siregar ${ }^{2}$ \\ ${ }^{1,2}$ STIKes Darmais Padangsidimpuan \\ email : julilubis17@gmail.com,nurhanifahsiregar90@gmail.com
}

\begin{abstract}
Vaginal discharge is vaginal discharge that is not blood which is sometimes a clinical manifestation of various infections, malignancies, or benign reproductive tumors, which always wet and cause irritation, itching and reduce comfort in sex. This study aims to determine the relationship with the incidence of flour albus in women of childbearing age in the Labuhan Rasoki Public Health Center, Southeast Padangsidimpuan District. The design of this research is an analytic survey with a cross sectional approach. The sampling technique used the solvin formula and obtained 30 respondents. Analysis of the data with univariate and bivariate analysis with a significance level of 0.05 . The results showed that there was a relationship between knowledge and the incidence of flour albus in women of childbearing age in the working area of the Labuhan Rasoki Public Health Center, Padangsidimpuan, Southeast with $p=0.000<p=0.05$. It is expected that respondents will increase their knowledge, especially about flour albus by actively participating in counseling and reading a lot from mass media and electronics.
\end{abstract}

Keywords: Flour Albus, women of childbearing age, knowledge

\section{PENDAHULUAN}

Kesehatan reproduksi adalah suatu keadaan sejahtera fisik,mental dan sosial secara utuh,tidak sematamata bebas dari penyakit atau kecacatan dalam semua hal yang berkaitan dengan system reprosuksi, serta fungsi dan prosesnya. Upaya memiliki kehidupan reproduksi yang sehat dan bertanggung jawab,berarti pula suatu upaya meningkatkan kualitas keluarga karena remaja adalah bagian dari suatu keluarga. Karena masalah kesehatan reproduksi pada setiap fase kehidupan dapat diperkirakan, maka apabila tidak ditangani dengan baik maka akan berakibat buruk bagi masa kehidupan selanjutnya (Widyastuti, n.d.).

Kesehatan reproduksi juga merupakan keadaan sejahtera fisik, mental dan social dalam segala hal yang berkaitan dengan system reproduksi pada semua tahap kehidupan . Kesehatan reproduksi yang secara implisit diartikan bahwa setiap orang dapat memiliki kehidupan seksual yang nyaman dan aman, serta kemampuan untuk 
berproduksi . Pria dan wanita harus memiliki pengetahuan dan akses ke motedo yang aman, efektif , terjangkau, dan dapat diterima kelurga berencana pilihan mereka ,dan hak untuk pelayanan kesehatan yang sesuai yang memungkinkan perempuan untuk menjalani kehamilan dan persalinan yang aman (Yusiana \& Saputri, 2016).

Masalah kesehatan reproduksi sering dialami oleh wanita yang sudah melalui atau merasakan menstruasi, salah satu masalah yang di hadapi adalah keputihan pada wanita. Keputihan ada yang berbahaya dan ada tidak berbahaya.

\section{Keputihan (Leukore/fluor}

albus) merupakan cairan yang keluar dari vagina dalam keadaan biasa,cairan ini tidak sampai keluar namun belum tentu bersifat patologis (berbahaya). Pengertian lain adalah setiap cairan yang keluar dari vagina. Selain darah dapat berupa sekret,transudasi atau eksudat dari organ atau lesi dari saluran genital.Cairan normal vagina yang belebih, jadi hanya meliputi sekresi yang berlebih, tidak termasuk eksudat. Keputihan yaitu cairan putih yang keluar dari liang senggama secara berlebihan (Yusiana \& Saputri, 2016).

Leucorrhea bukan penyakit tetapi gejala penyakit, sebab yang pasti perlu ditetapkan. Keputihan dapat disebakan oleh adanya bakteri,sepertigonococcus, chlamydia ,trichomatis ,gardenella ,treponena pallidum, adanya infeksi jamur seperti trichomonas vaginalis, serta adanya infeksi seperti condyloma taacuminata dan herpes. Oleh karena itu untuk menentukan penyakit dilakukan berbagai pemeriksaan cairan yang keluar. Keputihan sebagai gejala penyakit dapat ditentukan melalui berbagai pernyataan yang mencakup kapan ,dimana, berapa jumlahnya, apa gejalanya, (gumpalan atau encer, ada luka disekitar alat kelamin pernah disertai darah, ada bau busuk, menggunakan AKDR) adakah demam,rasa nyeri didaerah kemaluan.

World Health Organization (WHO, 2010) telah menyarankan negara-negara membangun untuk memanfaatkan penggunaan 
pengobatan tradisional dalam bidang kesehatan. Keputihan dapat dicegah melalui gaya hidup yang sehat seperti membersihkan vagina setelah buang air dengan gerakan dari depan ke belakang mengeringkan vagina dengan tisu sekali usap,dan tidak duduk di toilet karena keputihan dapt menular melalui bibir vagina kloset dan perlengkapan mandi seperti handuk. (Abrori, Hernawan, \& Ermulyadi, 2017).

wanita dalam usia refroduktif yaitu usia 15-49 tahun baik yang berstatus kawin,janda maupun yang belum nikah.Jumlah wanita yang pernah mengalami keputihan sekitar 75\%,sedangkan wanita Eropa yang mengalami keputihan sebesar $25 \%$, dan $75 \%$ wanita Indonesia yang mengalami keputihan (Yusiana \& Saputri, 2016).

Di Indonesia $75 \%$ wanita pernah mengalami keputihan minimal 1 kali dalam hidupnya dan setengah diantaranya mengalami keputihan sebanyak 2 kali atau lebih. Hal ini berkaitan dengan cuaca yang lembab yang mempermudah berkembangnya infeksi jamur. Keputihan patologi ddisebabkan karena pengetahuan yang masih kurang tentang keputihan. Keputihan yaitu cairan yang keluar dari liang sanggama secaraberlebihan .Sampai saat ini keputihan belum jelas penyebabnya bahkan persepsi wanita usia subur (WUS) belum mencakup yang berhubungan dengan keputihan . Keputihan abnormal dapat vterjadi pada semua infeksi alat kelamin, banyak faktor yang berpengaruh terhadap terjadinya keputihan antara lain, umur pendidikan, sumber informasi pengetahuan. Informasi tentang keputihan patologi merupakan hal yang penting untuk menghindari terjadinya keputihan fisiologi menjadi keputihan patologi.

Berdasarkan hasil penelitian dari (Nanur, Vivi, \& Mudah, 2020) bahwa dari $50 \%$ orang wanita usia subur di kawasan Asia Selatan terutama India yang terdekteksi Trikomoniosis Vaginalis sebanyak 3 kasus (6\%) dan Candida Albicans dalam 26 kasus (52\%). Terinfeksi Trikomoniosis Vaginalis sebanyak 4 kasus ( $8 \%$ ). Hampir $83 \%$ penyebab keputihan adala bakteri Candida Albicans yang banyak terjadi pada 
wanita usia subur ( WUS ) dan berasal dari pedesaan. .

Berdasarkan survey pendahuluan yang dilakukan oleh peneliti di Puskesmas Labuhan Rasoki Padangsidimpuan Tenggara, didapatkan 10 WUS yang diwawancarai 3 diantaranya belum mengetahui tentang perlunya personal hygine, dan 2 orang kurang mengetahui tentang flour albus.

Penelitian ini bertujuan
untuk mengetahui hubungan
pengetahuan dengan kejadian flour
albus pada wanita usia subur di
wilayah kerja puskesmas labuhan
rasoki padangsidimpuan tenggara.

\section{METODE}

Jenis penelitian ini adalah penelitian survey analitik dengan pendekatan cross sectional yang bertujuan untuk mengetahui hubungan pengetahuan dengan kejadian flour albus pada wanita usia subur di wilayah kerja puskesmas labuhan rasoki padangsidimpuan. waktu penelitian agustus - oktober 2021.
Populasi seluruh wanita usia subur 20-45 Tahun dengan kategori wanita usia subur yang sudah menikah di Puskesmas Labuhan Rasoki Padangsidimpuan Tenggara berjumlah 165 orang dan sampel dalam penelitian ini adalah seluruh wanita usia subur 20-45 Tahun dengan kategori wanita usia subur yang sudah menikah berjumlah 30 orang menggunakan teknik pengambilan sampel (simple random sampling).

Metode pengumpulan data penelitian ini mulai dari data primer, skunder dan tertier, instrumen yang di gunakan dalam penelitian ini adalah menggunakan kuesioner. Teknik analisa data yan digunakan adalah analisa univariat dan analisa bivariat.

\section{HASIL DAN PEMBAHASAN}

\section{Hasil}

Hasil penelitian berdasarkan pengetahuan wanita usia subur dengan kejadian flour albus Tabel 1 berikut: 
Tabel 1 Distribusi Frekuensi Pengetahuan wanita usia subur tentang kejadian flour albus di wilayah kerja Puskesmas Labuhan Rasoki Padangsidimpuan Tenggara

\begin{tabular}{clcc}
\hline No & \multicolumn{1}{c}{ Pengetahuan } & Frekuensi & Persentase (\%) \\
\hline 1 & Baik & 9 & 30 \\
2 & Kurang baik & 21 & 70 \\
& & 30 & 100 \\
\hline
\end{tabular}

Berdasarkan tabel di atas diperoleh hasil mayoritas pengetahuan responden adalah kurang dengan jumlah
21 orang $(70,0 \%)$, dan minoritas pengetahuan baik berjumlah 9 orang $(30,0 \%)$.

Tabel 2. Distribusi Frekuensi Hubungan Pengetahuan Wanita usia subur dengan kejadian flour albus di wilayah kerja puskesmas labuhan rasoki padangsidimpuan tenggara

\begin{tabular}{|c|c|c|c|c|c|c|c|c|}
\hline \multirow{3}{*}{ No } & \multirow{3}{*}{ Pengetahuan } & \multicolumn{4}{|c|}{ Flour Albus } & & & \multirow{3}{*}{$P$} \\
\hline & & \multicolumn{2}{|c|}{ Terjadi } & \multicolumn{2}{|c|}{$\begin{array}{c}\text { Tidak } \\
\text { terjadi }\end{array}$} & \multicolumn{2}{|c|}{ Jumlah } & \\
\hline & & $\mathbf{n}$ & $\%$ & $\mathrm{n}$ & $\%$ & $\mathbf{n}$ & $\%$ & \\
\hline 1. & Baik & 9 & 100 & 0 & 6.7 & 9 & 30 & \\
\hline \multirow[t]{2}{*}{2.} & Kurang Baik & 7 & 33.3 & 14 & 66.6 & 21 & 70 & 0.000 \\
\hline & Total & 16 & 53.3 & 14 & 46.7 & 30 & 100 & \\
\hline
\end{tabular}

Berdasarkan tabel diatas diperoleh hasil yang berpengetahuan baik yang mengalami keputihan flour albus sebanyak 9 orang (100\%) dan yang tidak mengalami tidak ada. Responden yang berpengetahuan kurang yang mengalami keputihan flour albus patologis sebanyak 7 orang $(33,3 \%)$ dan yang tidak mengalami sebanyak 14 orang $(66,6 \%)$.

Hasil uji Chi-Square diperoleh nilai $\mathrm{p}=0,000<0,05$ artinya ada pengaruh pengetahuan dengan kejadian flour albus pada wanita usia subur.

\section{Pembahasan}

Hasil penelitian menunjukkan bahwa yang berpengetahuan baik yang mengalami keputihan flour albus sebanyak 9 orang (100\%) dan yang tidak mengalami tidak ada. Responden yang berpengetahuan kurang yang mengalami keputihan flour albus sebanyak 7 orang $(33,3 \%)$ dan yang tidak mengalami sebanyak 14 orang $(66,6 \%)$.

Hasil uji Chi-Square diperoleh nilai $\mathrm{p}=0,000<0,05$ artinya ada pengaruh pengetahuan dengan kejadian flour albus pada wanita usia subur. 
Menurut (Notoatmodjo, 2010), pengetahuan merupakan hasil dari tahu, dan ini terjadi setelah seseorang melakukan penginderaan terhadap suatu objek tertentu. Penginderaan terjadi melalui panca indera manusia yakni indera penglihatan, pengdengaran, penciuman, rasa dan raba. Sebagian besar pengetahuan manusia diperoleh melalui mata dan telinga. Pengetahuan atau ranah kognitif merupakan domain yang sangat penting dalam membentuk tindakan seseorang (overt behavior).

Pengetahuan responden yang kurang tentang flour albus disebabkan mereka kurang mendapat informasi, padahal sumber informasi sekarang sudah banyak, bisa diperoleh dari tenaga kesehatan, teman dan media elektronik..

Penelitian yang dilakukan oleh (Nurhayati, 2013) hubungan pengetahuan dan perilaku vaginal hygiene dengan terjadinya keputihan dari 130 sampel diketahui $53,8 \%$ memiliki perilaku nrgatif terhadap vaginal hygiene. Perilaku berfungsi menyusuaikan diri dengan lingkungan, mengatur tingkah laku seseorang, mengatur perlakuan, dan peryataan kepribadian seseorang.

Hasil penelitian (RISKA, 2016), adanya hubungan tingkat pengetahuan ibu tentang personal hygiene dengan tindakan pencegahan keputihan $(\mathrm{p}=$
0,003). Pelayanan kesehatan akan mempengaruhi seseorang dalam berperilaku sehat termasuk menjaga kebersihan genetalian pada remaja.

Menurut asumsi peneliti, keputihan yang alami oleh setiap wanita berbeda-beda, tetapi ini menjadi masalah jika sudah mengalami tandatanda diluar ciri-ciri fisiologis. Pengetahuan yang baik atau ilmu pengetahuan yang di peroleh atau di miliki oleh wanita dapat mencegah terjadinya keputihan di luar batas normal, dengan pengetahuan yang baik maka dapat mengurangi terjadinya keputihan yang patologis dikarenakan jika terjadi keputihan pada wanita dan mengenali gejalanya sesuai dengan ilmu pengetahuan yang dimiliki maka wanita tersebut lebih mudah mengunjung fasilitas kesehatan.

\section{KESIMPULAN DAN SARAN}

\section{Kesimpulan}

Dapat disimpulkan bahwa ada hubungan pengetahuan dengan kejadian flour albus pada wanita usia subur di wilayah kerja Puskesmas Labuhan Rasoki Padangsidimpuan Tenggara.

\section{Saran}

Disarankan bagi agar dapat meningkatkan pengetahuan terkait flour albus.Memberikan motivasi kepada wanita usia subur untuk memperhatikan 
kebersihan atau personal hygiene daerak kewanitaan agar terhindar dari kejadian flour albus atau keputihan.

\section{DAFTAR PUSTAKA}

Abrori, A., Hernawan, A. D., \& Ermulyadi, E. (2017). Faktor yang berhubungan dengan kejadian keputihan patologis siswi SMAN 1 Simpang Hilir Kabupaten Kayong Utara. Unnes Journal of Public Health, 6(1), 24-34.

Nanur, F. N., Vivi, Y., \& Mudah, F. V. (2020). Gambaran Pengetahuan Wanita Usia Subur Tentang Flour Albus Di Dusun Sere Kelurahan Tanah Rata. Wawasan Kesehatan, $5(2), 43-48$.

Notoatmodjo, S. (2010). Promosi kesehatan.

Nurhayati, A. (2013). Hubungan Pengetahuan, Sikap, dan Perilaku Vaginal Hygiene Terhadap Kejadian Keputihan Patologis pada Remaja Putri Usia 13-17 Tahun di Daerah Pondok Cabe Ilir.

RISKA, S. (2016). Pengaruh Perilaku Ibu Terhadap Personal Hygiene Pada Balita Di Kecamatan Woyla Barat Kabupaten Aceh Barat. Universitas Teuku Umar Meulaboh.

Widyastuti, Y. (n.d.). Dkk, 2009, kesehatan Reproduksi.
Yogyakarta: Fitramaya, Info Media.

Yusiana, M. A., \& Saputri, M. S. T. (2016). Perilaku Personal Hygiene Remaja Puteri Pada Saat Menstruasi. Jurnal STIKES RS Baptis Kediri, 9(1). 